\title{
Para pensar o campo científico e educacional mulheres, educação e letras no século XIX
}

\author{
VÍVIAN MATIAS DOS SANTOS \\ Universidade Federal de \\ Pernambuco, Recife, PE, Brasil
}

\section{RESUMO}

Este artigo propõe uma contribuição para a abordagem de gênero das ciências por meio de "fragmentos historiográficos" sobre a participação de mulheres nos campos educacional, literário e científico. Trata-se de um estudo relativo a sujeitos, tempo e espaço específicos: mulheres que, durante os séculos XVIII e XIX, inseriram-se em espaços pensados por e para "homens de ciências e de letras" no estado do Ceará, Região Nordeste do Brasil. A maior contribuição desta discussão situa-se na tarefa de conhecer os discursos e práticas que envolveram as mulheres no campo científico antes da criação das primeiras universidades.

\section{PALAVRAS-CHAVE}

gênero; ciências; educação; literatura. 


\title{
TO THINK SCIENTIFIC AND EDUCATIONAL FIELD: WOMEN, EDUCATION AND LETTERS IN THE 19th CENTURY
}

\begin{abstract}
This article proposes to contribute to the gender approach of science through "historiographical fragments" about women's participation in the educational, literary and scientific fields. This is a study relating specific individuals, specific time and space: women who, during the XVIII and XIX centuries, were inserted into places conceived by and for "men of science and letters" in the State of Ceara, situated in the northeast region of Brazil. The main contribution of this discussion is to know discourses and practices that women were involved in the scientific field before the creation of the first universities.
\end{abstract}

KEYWORDS

gender; science; education; literature.

\section{PENSAR EN EL ÁMBITO CIENTÍFICO Y EDUCATIVO: MUJERES, EDUCACIÓN Y LETRAS EN EL SIGLO XIX}

\section{RESUMEN}

En este trabajo se propone una contribución al investigaciones de género de la ciencia a través de algunas "fragmentos de la historia" de la participación de las mujeres en los ámbitos de la educación, literatura y ciencia. Se trata de un estudio acerca de las personas, tiempo y espacio específicos: las mujeres que, durante los siglos XVIII y XIX, se insertaron en los espacios diseñados por y para los "hombres de ciencia y letras" en el Estado de Ceará, emplazado en Noreste de Brasil. La principal contribución de este debate radica en la tarea de satisfacer los discursos y prácticas que involucran a mujeres en el ámbito científico antes de la creación de las primeras universidades.

PALABRAS CLAVE

género; ciencia; educación; literatura. 


\section{CAMINHOS PARA REPENSAR OS SABERES CIENTÍFICOS}

"De repente, não mais que de repente". Diferente de como o poeta Vinícius de Morais (1991) entendeu a separação entre os amantes, a separação entre "viver" cotidianamente uma realidade complexa e "perceber" nessa mesma realidade um aspecto a ser pensado, questionado, não ocorre num rompante e nem sob quaisquer condições. Construo essa discussão tomando como exemplo um campo de estudos específico: são inúmeras as possíveis compreensões sobre ciência utilizando o gênero como categoria analítica.

Para começar, imaginemos que a realidade complexa citada seja o processo de construção das ciências que hoje se dá no espaço acadêmico, na universidade. Não é óbvio que todos os sujeitos que compõem o cenário das universidades percebam em sua dinâmica as relações de gênero, as quais enviesam tanto a constituição de suas estruturas objetivas e cognitivas (Bourdieu, 2005, 2007) quanto a composição de uma performance específica desse campo. Assim, transformar em objeto de pesquisa a problemática participação das mulheres nos loci de produção do conhecimento científico requer um olhar diferenciado.

É necessário o estranhamento das estruturas que comumente se observam na dinâmica das ciências, como a divisão sexual do trabalho (Hirata, 2002) nas diversas áreas de conhecimento, ou, como diria Schienbinger (2001), a segregação sexual territorial e hierárquica. É socialmente apreendido como natural o fato de mulheres serem mais presentes nas humanidades, letras e artes, enquanto os homens ainda são a esmagadora maioria nas áreas tecnológicas e nas ciências supostamente "exatas".

Discursos e práticas discriminatórias passam despercebidos no cotidiano dos fazeres científicos. É naturalizado o fato de as mulheres ainda serem pouco expressivas em determinadas áreas, ou mesmo o fato de terem maiores dificuldades em ocupar cargos decisórios, não somente no âmbito da universidade, mas no seio da política, da ciência e da tecnologia nacional (Matias dos Santos, 2007).

Nas ciências também se estabelecem relações imersas nas teias do cotidiano e, sendo a cotidianidade marcada pelo pragmatismo, imediatismo, superficialidade e pelos pensamentos fragmentados (Heller, 2008), emerge a necessidade de um distanciamento para que possam existir reflexões mais profundas. No distanciamento habita uma considerável fecundidade intelectual, na medida em que esse exercício torna possível, aos poucos, revelar a estranheza daquilo que é tido como familiar. "Compreender menos, ser ingênuos, espantar-se, são reações que podem nos levar a enxergar mais, a apreender algo mais profundo [...]” (Ginzburg, 2001, p. 29). Essa postura intelectual é indispensável para o processo de percepção das relações de poder que se estabelecem entre cientistas de ambos os sexos. O distanciamento e o estranhamento tornam-se especialmente indispensáveis pelo fato de eu, como mulher e pesquisadora, também fazer parte desse universo.

Tal postura requer um empenho considerável, visto que, como afirma Bourdieu (2005, p. 18), “a visão androcêntrica impõe-se como neutra”. Assim, 
inúmeras vezes, por meio de uma socialização das diferenças biológicas e de uma biologização do social, cientistas elaboraram uma linguagem para as ciências balizada na desigualdade de gênero.

\section{CIÊNCIAS: UMA CONSTRUÇÃO SOCIAL}

Antes de adentrar nas discussões que este artigo propõe realizar, convêm alguns esclarecimentos: Como as "ciências" são compreendidas neste estudo? Em qual universo científico estão situadas as análises aqui empreendidas? O ponto de partida desta discussão é a compreensão de que as ciências são uma construção social (Haraway, 2001) e que, portanto, não há uma "ciência" única, mas "ciências" consolidadas por uma "multiplicidade de visões", visto que são construídas por sujeitos diversos, em tempos e lugares também diversos. Nesse sentido, considero relevante explicitar que as reflexões aqui construídas estão ancoradas na crítica específica à "ciência moderna e ocidental".

Bourdieu (2004), ao considerar as ciências como um campo, afirma que sua dinâmica de construção é permeada por uma contradição permanente e inevitável: por um lado, percebe-se no campo científico a influência de fatores históricos, econômicos e culturais inerentes às sociedades em que está situado, ou seja, as ciências são influenciadas por fatores externos à sua dinâmica peculiar; por outro lado, o campo científico, como qualquer campo social, possui leis, normas particulares que demandam um habitus específico, que regulam as ações de agentes e instituições que o compõem; melhor dizendo, existem, para além de influências externas, leis internas que conferem especificidades ao campo científico. Portanto, nesse "universo construído por agentes e instituições, devem ser percebidas suas próprias leis, mas, por se intercruzar com outros campos sociais (pressões externas), pode-se perceber que a autonomia do campo científico se dá de forma relativa” (Matias dos Santos, 2012).

Nesse aspecto, ao reconhecer a heteronomia das ciências, já que carregam as marcas históricas, econômicas e culturais das sociedades em que se estruturam, pode-se afirmar que existem especificidades no "campo científico moderno". Boaventura de Sousa Santos $(2006,2009)$ denuncia que, ao afirmar a expressão "ciência moderna”, estamos na realidade nos referindo a uma ciência específica, a qual, "para além de ocidental e capitalista, [...] é sexista" (Santos, 2009, p. 87).

$\mathrm{O}$ autor defende que é inerente à racionalidade da "ciência moderna ocidental" a construção de dicotomias que edificam hierarquias, tais como: cultura/ natureza; ciência/senso comum; razão/emoção; sujeito/objeto, entre tantas outras que demarcam a maneira pela qual se articula essa racionalidade. "Estes dualismos são sexistas na medida em que, em cada um deles, o primeiro polo é considerado dominante, sendo ao mesmo tempo associado com o masculino" (idem, p. 88). O "diferente" é tratado racionalmente como "desigual". Nos termos desse pensamento hierarquizante, na dicotomia homem/mulher, as mulheres são imaginadas como seres não racionais em que as paixões predominam, mais próximas da natureza, do senso comum. Desse modo, as mulheres são invisibilizadas, construídas 
discursivamente como ausentes nos meandros das relações de poder estabelecidas ao longo da história das ciências na modernidade ocidental.

É relevante nos atentar, entretanto, para o fato de o sexismo não ser uma exclusividade moderna. Nas sociedades do Ocidente, hegemonicamente, por meio de sua autoridade, as ciências têm legitimado discursos sexistas. Na Antiguidade Grega, por exemplo, Aristóteles (384-322 a.C.), na Metafísica, afirmou a inferioridade física, mental e espiritual das mulheres. Teorizando acerca dos genos, declarou que na reprodução humana a mulher seria apenas uma espécie de "depósito" no qual o homem guardaria sua semente (sêmen) para a geração de um novo ser. Ela, por sua vez, não transmitiria suas características genéticas ao filho, sendo somente o homem o responsável por "dar a forma" ao descendente. Aristóteles afirmou, ainda nessa obra, que os corpos femininos são inacabados, "como o corpo de uma criança, cujo sêmen é estéril e o cérebro é menor que o do homem" (Chassot, 2003, p. 45). Vale dizer que no discurso ontológico aristotélico a oposição forma/matéria corresponde aos dualismos homem/mulher, razão/natureza, em que complementaridade não significa igualdade, pois na existência dos dois sexos a forma (homem) seria mais divina que a matéria (mulher) (Puleo, 2002).

$\mathrm{Na}$ história mais recente das ciências ocidentais, na sociologia do século XIX, destaca-se o discurso produzido por Emile Durkheim. Em sua obra Da divisão do trabalho social, influenciado pelo darwinismo social, utilizou-se de estudos antropológicos para afirmar a inferioridade das mulheres. De acordo com o autor, esses estudos revelavam que nas sociedades "primitivas" as diferenças entre o corpo feminino e o masculino eram bem menores que nas sociedades "evoluídas". Essa afirmação tinha como fundamento pesquisas realizadas por meio de crânios de seres humanos pertencentes a sociedades e épocas variadas. Tais investigações teriam constatado que, com a civilização, somente os crânios masculinos teriam evoluído. Para Durkheim, as dessemelhanças anatômicas seriam, necessariamente, acompanhadas de dessemelhanças funcionais (Durkheim, 1989). ${ }^{1}$

Assim, tendo em vista a suposta inferioridade craniana e a consequente menor inteligência das mulheres, para o autor as ciências significariam um espaço destinado aos homens.

O discurso durkheimiano, inaugural na sociologia e por muito tempo hegemônico nessa disciplina, fez crer no argumento de que, se, com a "evolução" da sociedade, a mulher cada vez mais se distinguia fisicamente do homem, seria natural que as funções desempenhadas por cada sexo fossem progressivamente diferenciadas. E, mais além, "se, com a evolução biológica, as mulheres se encontrariam

1 Nesse sentido, Durkheim defendia que "ao ver, em certas classes, as mulheres ocuparem-se como os homens da arte e da literatura, poder-se-ia crer, é verdade, que as ocupações dos dois sexos tendem a tornar-se homogêneas. Mas mesmo nesta esfera de acção a mulher aplica a sua natureza própria, e o seu papel permanece muito especial, muito diferente do do homem. Além disso, se a arte e as letras começam a tornar-se coisas femininas, o outro sexo parece abandoná-las para se entregar mais especialmente à ciência $[$ sic]" (Durkheim, 1989, p. 75). 
em patamar inferior ao dos homens, provavelmente os papéis atribuídos ao sexo feminino seriam socialmente aceitos como hierarquicamente inferiores" (Matias dos Santos, 2007, p. 135).

Aristóteles e Durkheim são apenas dois entre os incontáveis nomes de cientistas possíveis de serem apontados como porta-vozes do discurso androcêntrico nas ciências. Dessa forma, o ato de colocar em questão uma suposta dominação masculina no campo científico diz respeito a desafiar intelectual e politicamente uma ordem masculina que "dispensa justificação" (Bourdieu, 2005, p. 18). Nesse sentido, a abordagem de gênero das ciências ocorre pelo conflito, pois pode atingir diretamente a autoridade científica ao percebê-la como produtora de um discurso legitimador da inferiorização da mulher e daquilo que se concebe como feminino.

Arquitetar um campo de estudos situado dentro da tarefa de compreender as ciências numa perspectiva de gênero tem, como se pode notar, seus desafios. A categoria gênero, nesse terreno de investigação, carrega em si a subversão dos discursos que reiteram a autoridade científica, pois denuncia que três dos aspectos fundamentais do fazer científico - a forma de organização do trabalho social da ciência; a identidade individual dos sujeitos que a constroem; e os próprios esquemas conceituais e crenças que "estruturam" essa mesma ciência - têm como base não as noções modernas de neutralidade e objetividade, mas o sexismo (Harding, 1996).

Do ponto de vista feminista, o estudo sobre as ciências pode ser mais rico à proporção que transitar por distintas disciplinas, tais como a história, a filosofia, a literatura, a sociologia, a educação. Entretanto, a proposta teórico-metodológica inter, multi e transdisciplinar não deve significar a negação das especificidades disciplinares, mas sim "fomentar o trânsito entre as áreas, policiar menos as fronteiras, e tentar 'desconstruir' as disputas por espaços e poderes dentro do mundo acadêmico que impedem o crescimento do diálogo" (Adelman, 2004, p. 171).

Nesse sentido, este artigo propõe um diálogo interdisciplinar que proporcione elementos para uma reflexão historicizada da participação das mulheres nas ciências, tomando como referência alguns dos caminhos por elas percorridos, em momentos anteriores ao século XX, num lugar específico: o estado do Ceará, pertencente à Região Nordeste do Brasil.

É importante reiterar que todo e qualquer conhecimento científico ou tecnológico é um constructo social, como defende Donna Haraway (2001). Isso nos leva à ideia de que todos os conhecimentos, para serem compreendidos, devem ser localizados e datados. Onde esses conhecimentos são produzidos? Em que momento e em que condições objetivas e discursivas? Como os sujeitos participam desses fazeres científicos?

Todos os conhecimentos são "situados" (Haraway, 1995), carregam em si as marcas de seu lugar, tempo e sujeitos. Assim, torna-se relevante o desvelamento da presença de mulheres em espaços específicos em que se podia observar um "trânsito" de conhecimentos científicos: no âmbito educacional, bem como nas instituições literárias e científicas. Nesse sentido, não deve haver a pretensão de universalizar os "fragmentos historiográficos" contidos neste estudo, ao contrário, deve-se ter a 
ambição de proporcionar reflexões apostando que "apenas uma perspectiva parcial promete uma visão objetiva” (idem, p. 21).

\section{MULHERES DELINEANDO UM CAMPO CIENTÍFICO ESPECÍFICO}

Há um entrecruzamento, nem sempre tão óbvio, entre os campos científico e educacional. A inserção no campo educacional por meio do acesso à educação formal foi e continua sendo condição primordial para que os sujeitos tenham possibilidade de se inserirem no campo científico e nesse espaço construir a carreira profissional. Nesse aspecto, é relevante levar em consideração que o campo educacional moderno, assim como as ciências, foi demarcado pelo discurso sexista. Na Europa, durante o século XVIII, a pedagogia moderna surge reatualizando o tradicionalismo ao pensar práticas educativas articuladas à lógica da divisão sexual do trabalho.

Para fundamentar essa tese de que o discurso sexista fez-se também presente na emergência do pensamento pedagógico moderno, destaco o tratado educativo Emílio ou da educação, escrito por Jean-Jacques Rousseau, considerado um marco revolucionário que alicerçou as práticas educacionais modernas na Europa durante os séculos XIX e XX, tornando-se hegemônico nos países ocidentais (Matias dos Santos, 2007). Nessa obra, enquanto Rousseau defende para os meninos a liberdade, pensa para as meninas uma educação apoiada na contínua repressão, de modo que as acostumasse à obediência e às tarefas do âmbito doméstico. No livro $V$ de Emílio, pode-se ler:

Toda a educação das mulheres deve ser relativa aos homens. Agradar-lhes, ser-lhes útil, fazer-se amar e honrar por eles, educá-los quando jovens, cuidar deles quando grandes, aconselhá-los, consolá-los, tornar suas vidas agradáveis e doces: eis os deveres das mulheres em todos os tempos, e o que lhes deve ser ensinado desde a infância. (Rousseau, 2004, p. 527)

Em Rousseau, uma educação baseada na razão deveria ser exclusividade masculina. "A fronteira da razão em Rousseau passou a ser determinante e determinada pela divisão sexual de papéis sociais” (Matias dos Santos, 2007). Para o pensador, "uma vez que se demonstrou que o homem e a mulher não são e nem devem ser constituídos da mesma maneira, nem quanto ao caráter, nem quanto ao temperamento, segue-se que não devem ter a mesma educação" (Rousseau, 2004, p. 524). Consequentemente, a defesa de uma educação desigual para homens e mulheres vincula-se à ideia de que o universo do conhecimento científico é um espaço, por excelência, masculino.

O Brasil, embora tenha uma história educacional específica, sofreu forte influência do pensamento educacional europeu (Ribeiro, 2000). Dessa forma, defendo que é nesse contexto - moderno, ocidental e sexista - que os microcosmos da educação, das ciências e das letras no estado do Ceará devem ser compreendidos e situados. 
Tendo em vista que o campo científico é "o universo no qual estão inseridos os agentes e as instituições que produzem, reproduzem, ou difundem [...] a ciência" (Bourdieu, 2004, p. 20), hoje, grande parte das tentativas de compreender a inserção de mulheres nesse campo tem como referencial empírico as universidades, visto que estas representam os espaços em que, predominantemente, produzem-se conhecimentos científicos e tecnológicos e, por consequência, são lugares em que mulheres e homens constroem suas carreiras como cientistas. $\mathrm{O}$ espaço das universidades também se traduz como um campo para análises fecundas acerca da incessante interlocução e, por que não afirmar, interdependência entre os campos da política científica e educacional no país.

No Ceará, a primeira universidade - atualmente a Universidade Federal do Ceará (UFC) - foi instituída na década de 1950. A tarefa de tentar conhecer, numa perspectiva de gênero, o processo de construção do conhecimento científico nessa universidade específica emerge como importante contribuição para as pesquisas sobre a história das ciências e da educação cearense. Contudo, para melhor fundamentar tal empreitada, considero indispensável a busca pelas seguintes compreensões, eixos analíticos deste estudo: Antes do século XX, quando não existiam universidades no estado do Ceará, como se poderia pensar a presença das mulheres nas ciências? Que caminhos elas percorreram? Em que lugares atuavam? Que exigências deveriam cumprir? Como foram conhecidas? Foram reconhecidas?

Em sua análise acerca dos estudos produzidos sobre gênero e ciências no Brasil, Margaret Lopes (idem, p. 61) afirma que essa ainda é uma história a ser escrita. Especialmente no que se refere à caracterização dessa problemática em momentos anteriores ao século XX. Para a autora, "interessa mais do que um levantamento das poucas e possíveis primeiras mulheres a se profissionalizarem, observar o conjunto dos discursos e práticas no qual as mulheres foram envolvidas e se envolveram ao longo de todo o século XIX". Entre tais discursos e práticas, destacam-se aqueles presentes no âmbito da imprensa, literatura e educação.

Assim, a pesquisa documental ${ }^{2}$ possibilitou o desvendamento de alguns discursos e práticas presentes nos caminhos trilhados pelas mulheres ao longo dos dois séculos que precederam o século XX no Ceará. Nesta discussão, uma especial atenção foi dada à presença de mulheres no campo educacional, no qual exerceram a docência e receberam uma instrução específica para o seu sexo. Embora muitos nomes de mulheres sejam aqui mencionados, a intenção, concordando com o que propõe Lopes (idem), não é fazer um levantamento de mulheres que se destacaram,

2 A pesquisa documental foi realizada durante os anos de 2009 e 2010 no Arquivo Público do Estado do Ceará (APEC), no Instituto do Ceará Histórico, Geográfico e Antropológico e na Academia Cearense de Letras. Neste estudo, destaca-se a pesquisa realizada no APEC, que teve como fonte específica o "Índice da Instrução Pública", no qual estão catalogados os documentos oficiais da educação pública do Ceará relativos ao período de 1833 a 1889 . Nesse índice podem ser encontrados documentos como legislações, cartas, ofícios, relatórios e processos movidos contra professores contratados pela Secretaria de Educação e Cultura do Estado. 
mas compreender como os discursos consolidaram um campo científico cearense que se mostrou muitas vezes hostil à participação feminina.

\section{"FRAGMENTOS HISTORIOGRÁFICOS" - 3 TRAJETOS DE FORMAÇÃO E DOCÊNCIA}

No final do século XVI havia somente onze "escolas de leituras" na capitania do Ceará (Castelo, 1943). Nesse contexto, a docência não era percebida como um ofício tipicamente feminino. Os professores, naquele período, tinham de ensinar "não só a boa forma dos caracteres, mas também as regras de ortografia portuguesa e sintaxe, as quatro operações ariméticas [sic] simples, o catecismo cristão, e regras de civilidade" (idem, p. 55).

A instrução secundária, o que se conhecia como "estudo de humanidade", correspondia ao ensino do latim. ${ }^{4}$ Em poucos lugares da capitania havia essa modalidade de ensino. O latim era ensinado somente em Fortaleza, Aquiraz, Aracati, Icó, Vila-Viçosa e Sobral (idem). Nesses lugares, na docência permanecia a presença masculina.

3 Neste momento do texto, opto pela utilização do termo "fragmentos historiográficos" por compreender as limitações do corpus empírico aqui tratado por meio da pesquisa documental, tendo em vista que somente foram inventariados e analisados alguns dos diversos documentos pertencentes ao "Índice da Instrução Pública (1833-1889)": aqueles que, de alguma maneira, mencionavam a atuação de mulheres como docentes. Por esse motivo, não há aqui a pretensão de consolidar um profundo conhecimento acerca do campo educacional cearense deste período, que contemple toda a sua lógica de institucionalização e hierarquização. Há, sim, a intenção de contribuir para as reflexões acerca dos discursos e práticas que permearam a participação feminina nesse espaço e tempo específicos, não havendo a intenção de esgotar as possibilidades analíticas suscitadas por essa problemática.

4 O estudo do latim era ainda considerado indispensável para aqueles que desejavam ter acesso às principais produções intelectuais vindas da Europa. Nos séculos em que a Igreja católica monopolizava o conhecimento científico e filosófico, não somente a missa era rezada em latim, como as escrituras consideradas sagradas e todas as produções intelectuais reconhecidas pelo campo científico e religioso eram publicadas nessa língua. Martinho Lutero (1483-1546), idealizador da Reforma Protestante, conseguiu grande adesão às suas ideias em virtude da publicação de seus escritos ter sido na língua alemã. Lutero foi o primeiro a traduzir a Bíblia Sagrada para o Alemão, transgredindo as normas estabelecidas pela Igreja. De acordo com Guibernau (1997), a publicação de textos nas línguas vernáculas foi resultante de um longo processo e esteve vinculado à consolidação dos Estados Nacionais, que tentavam estabelecer em seus territórios sistemas educacionais de base nacional. "Na Europa, antes da segunda metade do século $\mathrm{XV}, \mathrm{o}$ acesso à leitura e à escrita era privilégio de alguns mercadores bem-sucedidos, da nobreza e do clero. Gradualmente, as mais variadas formas de comunicação escrita foram deixando de ser padronizadas por meio do uso do latim, para se tornarem acessíveis às demais línguas pátrias” (Matias dos Santos, 2007, p. 47). 
No século XVIII, no mesmo ano em que foram expulsos os jesuítas, ${ }^{5} \mathrm{em}$ 1759, criaram-se as primeiras escolas públicas do Ceará. Era um período em que, na organização do ensino, prevaleciam os interesses locais: "sem sistema, nem método, perduraria, de 1759 a 1772, [...] sem o auxílio ou subvenção que pudesse proporcionar iniciativas louváveis" (idem, p. 52).

Em 1799, pela primeira vez na história do Ceará, uma mulher foi nomeada professora, D. Ana Clara da Encarnação, que se dedicaria ao ensino de meninas da Vila de Soure, com a criação da "cadeira de ler, escrever e contar do sexo feminino" (idem). Desde a expulsão dos jesuítas até a "Independência”, em 1822, foram fundadas 27 escolas no Ceará e para as quais se nomearam 16 professores e somente 2 professoras: uma delas, D. Ana Clara,já mencionada, e D. Maria Gertrudes Ferreira, também professora de "ler, escrever e contar para o sexo feminino", nomeada em 1808, em Fortaleza.

Nesse momento histórico, devemos nos atentar para uma questão: dos dezoito professores nomeados no Ceará, apenas as duas referidas se ocuparam da educação de meninas. Delineava-se, então, um cenário que negligenciava, formalmente, a relevância da educação feminina. Entretanto, as possibilidades de uma educação oficial voltada para mulheres não se limitava às vagas ofertadas pelo Estado. Nos sertões nordestinos, raramente as mulheres aprendiam a ler, ou, sequer, assinar o nome. Aquelas que tinham acesso a alguma instrução, eram pertencentes às elites. Assim, tinham uma professora particular que lhes deveria ensinar, primordialmente, as "prendas do lar".

Mesmo as mulheres pertencentes às classes mais abastadas não tinham acesso igualitário à educação. Discursivamente, se não podiam exercer funções como as atribuídas aos homens, também não deviam ter acesso aos mesmos conhecimentos que eles.

Muitas apenas conheceram as primeiras letras e aprenderam a assinar o nome. Enquanto seus irmãos e primos do sexo masculino liam Cícero, em latim, ou Virgílio, recebiam noções de grego e do pensamento de Platão e Aristóteles, aprendiam ciências naturais, filosofia, geografia, francês, elas aprendiam a arte de bordar em branco, o crochê, o matiz, a costura e a música. (Falci, 2004, p. 251)

5 Acerca da educação pensada pelos jesuítas, foi registrado que, mesmo antes de Portugal, já havia sido pensado para a colônia um projeto de educação feminina. A ideia inédita foi de padre Manuel da Nóbrega. "Aos índios, tangidos por uma cultura simples [...], era inconcebível o condenar à ignorância o sexo feminino estabelecendo diferença de oportunidades educacionais a favor do sexo masculino. Entusiasmado, elaborou Nóbrega um projeto de educação para a mulher e, tendo conquistado apoio de Tomé de Sousa e demais personalidades da administração colonial, acreditou poder apelar à corte, com sucesso, e receber o patrocínio da Rainha D. Catarina. O Brasil pedia demais... O que a Metrópole não cogitava nem para si própria, em 1552 Nóbrega já pedia para o Brasil"(Camurça, 1968, p. 198). Foi somente em 1815 que Portugal sancionou a criação de escolas destinadas à educação feminina. 
No sertão do Ceará, merece menção a pedagogia cristã destinada às mulheres e desenvolvida nas casas de caridade criadas pelo cearense padre Ibiapina. ${ }^{6}$ Entre os anos 1860 e 1875, padre Ibiapina ergueu vinte dois abrigos nos estados da Paraíba, Pernambuco, Rio Grande do Norte e Ceará. Esse espaço merece um olhar atencioso, pois "[...] é preciso dizer que estas instituições tinham múltiplas funções, não serviam apenas de abrigo para "a orphan $[s i c]$, a mulher perdida e a virgem que queria refugiar-se ao pé dos altares do Senhor”. Era um lugar de referência para os indigentes da Região Nordeste" (Madeira, 1997, p. 2). O cotidiano educacional nessas instituições movia-se por meio de um tripé: trabalho, estudo e oração. Havia ali a intenção de "alentar o trabalho e moralizar o povo" (idem, ibidem).

O discurso em torno do qual se movia a experiência educacional dos abrigos de Ibiapina era, assim como em outras instituições educacionais, calcado na lógica da divisão sexual do trabalho. As mulheres abrigadas, além de receber forte educação moral, exerciam atividades vinculadas aos afazeres domésticos: cozinhavam, limpavam, cuidavam dos animais domésticos, da horta-escola. Ainda fabricavam tecidos, chapéus de palha, faziam bordados e crochê, costuravam. Além disso, também acolhiam as crianças abandonadas, romeiros e os pobres retirantes que vinham em busca dos "conselhos" do padre (idem).

Entretanto, o destaque que esses abrigos merecem no âmbito da educação oferecida às mulheres sertanejas do Ceará do século XIX, além de se vincular ao fato de proporcionarem instrução para mulheres desfavorecidas econômica e socialmente, ${ }^{7}$ vincula-se também ao fato de já poderem ser observados traços da pedagogia moderna, pois a intenção era de ensinar um ofício àquelas mulheres, para que pudessem ter o seu sustento sem, todavia, romper com a lógica da educação doméstica.

No que se refere mais amplamente ao cenário da educação pública cearense, somente em 1827, com a carta de lei de 15 de outubro, assinada por D. Pedro I, foi instituído que em todas as cidades, vilas e lugarejos populosos deveria haver "Escolas de Primeiras Letras". Nelas, de acordo com o artigo $6^{\circ}$ da referida lei, "os professores, além de ensinar a ler e escrever, deveriam lecionar as quatro operações de arimética [sic], quadrados, decimais e proporção, geometria prática, gramática, e os princípios de moral cristã e da doutrina da religião católica, apostólica, romana" (Carta de lei de 15 de outubro de 1827 apud Castelo, 1943, p. 64).

6 "Antônio de Maria Ibiapina (1806-1883), nascido em Sobral/CE, teve uma vida atribulada: a mãe morrera cedo; perdera o pai e o irmão, vitimados pela Confederação do Equador, ocorrida em 1824. Passou brevemente pelo Seminário de Olinda, em 1823 e 1828; fez o curso Jurídico de 1828 a 1832, foi juiz de direito - nomeado em 1833 para a comarca de Campo Maior (Quixeramobim/CE) -, deputado geral da Província do Ceará (legislatura de 1834/1837); professor de Direito Natural Jurídico do Curso de Olinda, em 1833, do qual foi aluno, e por fim padre, aos 46 anos” (Madeira, 1997, p. 2).

7 "As mulheres acolhidas, em geral, não apresentavam um perfil único, pois eram solteiras, casadas, viúvas, mulheres de vida considerada errante, muito embora, grande parte delas, ou talvez as mais destacadas pelos memorialistas, pertencessem a famílias abastadas" (Madeira, 1997, p. 5). 
Nessa mesma legislação, já se percebe a discussão acerca da educação pública destinada às meninas, porém ainda não percebida como prioridade, tal qual era a educação de meninos. No artigo 11, estabelecia-se que deveria haver escolas de meninas nos lugares mais populosos, mas somente se as autoridades locais assim julgassem necessário.

Além da condição inferior em que se encontrava a educação pública feminina naquele momento, é fundamental perceber que os conteúdos a serem ministrados às meninas deveriam ser diferentes: "Art. 12 - As mestras, além do declarado no artigo $6^{\circ}$, com exclusão das noções de geometria e limitando da arimética só às quatro operaçôes, ensinarão também prendas que servem à economia doméstica" (idem, p. 65, grifos meus).

Nessa legislação era legitimado o discurso que segregava territorial e hierarquicamente os papéis que deveriam ser assumidos por cada sexo. Isso pode ser pensado tendo como base as ideias de Kehl (1996), que, valendo-se da literatura e do discurso psicanalítico, aponta algumas particularidades de nossa cultura ocidental sexista: a mulher não tem lugar de sujeito no pacto civilizatório; ela é percebida como menos racional e mais inclinada aos prazeres do amor.

A mulher seria, então, objeto de disputa entre os sujeitos da civilização, os homens. Com base nesse discurso, práticas foram tecidas tendo como alicerce a contraposição de duas éticas: a ética privada, feminina; e a ética pública, considerada masculina. Teríamos assim "uma ética que prioriza o prazer contra uma outra que procura antes de tudo evitar o desprazer" (idem, p. 37, grifos do original). Desprazer este que poderia ser proporcionado pela participação feminina em lugares tidos como masculinos: a ciência, a política, por exemplo.

Mais tarde, com a dinamização do processo de modernização, foi esse mesmo "amor", ao qual as mulheres seriam naturalmente inclinadas, que as legitimou como propensas para o magistério de crianças. Durante o século XIX, podemos observar discursos que reiteravam essa percepção da mulher e do feminino. Antônio de Almeida Oliveira (1843-1887), por exemplo, que dedicou grande parte de sua vida à educação da província do Maranhão, de Santa Catarina e da Corte, afirma: “[...] a natureza pôs a razão no homem e o amor na mulher. Daí vem que a civilização pede ao homem o concurso da razão, à mulher, o do amor"(Oliveira, A. A., 2003, p. 322).

Para Oliveira, se a civilização deve muito aos homens pela razão que lhes seria natural, o processo civilizatório também teria grande dívida para com as mulheres, visto que os grandes avanços deveriam ser contados pelos "progressos da educação". $\mathrm{E}$ o que seria, então, a educação? Seria "a arte de nos tornar bons"(idem, ibidem). E, para nos fazer "bons", nada seria mais adequado que o suposto amor maternal feminino.

\section{COMO DEVERIAM SER AS PROFESSORAS NO SÉCULO XIX?}

Desde o século XVI, de acordo com os registros de Castelo (1943), a educação no Ceará era afligida por um grave problema: os professores, muitas vezes, eram semianalfabetos ou alfabetizados rudimentarmente. De acordo com o autor, eles não tinham uma formação à altura para a docência. Isso ocorria em virtude do baixo 
salário e das condições precárias de trabalho. Assim, os homens verdadeiramente letrados não se viam atraídos pelo magistério.

Com o decreto de 15 de outubro de 1827, algumas melhorias foram consolidadas no que se referia ao ofício de professor. Foram garantidos os seguintes direitos a esses trabalhadores: a vitaliciedade; adicionais por tempo de serviço; cursos de aperfeiçoamento. Contudo, "os vencimentos bastante majorados não lograram despertar a atenção dos mais letrados de então, aliás, bastante raros" (Castelo, 1943, p. 68).

Em virtude das precárias condições do trabalho docente no Ceará, bem como das novas oportunidades surgidas para os homens nos espaços públicos, gradualmente as mulheres foram se inserindo no magistério destinado às crianças fato ocorrido também em outros lugares do Brasil. "Afinal, estas eram as mães e futuras mães" (Almeida, 2005, p. 68). A mulher teria "mais facilidade, mais geito de transmitir aos meninos os conhecimentos que lhes devem ser comunicados [...] Nella predominam os instintos maternaes, e ninguém como ella possue o segredo de captivar a attenção de seus travessos e inquietos ouvintes [sic]"(Cavalcante, 1884 apud Almeida, 2005, p. 68).

Desse modo, no Ceará destaca-se, inicialmente, a atuação feminina no ofício de ministrar as primeiras letras durante o século XIX - aliás, então único nível de ensino ao qual as meninas tinham acesso. O magistério representava uma estratégia para as mulheres se inserirem no mercado de trabalho, mesmo que a oportunidade tivesse como base a reiteração do discurso que afirmava nas mulheres mais sentimento e menos razão - o que seria um forte alicerce para a sua marginalização nos assuntos científicos e intelectuais de maneira geral.

Em contrapartida, a educação secundária permaneceu, até as primeiras décadas do século XX, um ofício masculino. Esse fato pode ser percebido quando, no período compreendido entre 1918 e 1930, foi registrado somente uma única mulher como professora do Liceu do Ceará: ${ }^{8}$ Henriqueta Galeno ${ }^{9}$ (Oliveira, J. C., 2007).

Essa predileção [por homens na educação], segundo o autor da época, Alberto Schiz, (citado no Relatório do Governo do Ceará de 1919), dava-se pelo fato

8 O Colégio Liceu do Ceará foi criado oficialmente pela lei n. 304, de 15 de julho de 1844. Seu primeiro diretor foi Thomaz Pompêo de Souza Brasil. É o terceiro colégio mais antigo do Brasil e surge inspirado no Colégio D. Pedro II, uma instituição-modelo de ensino criada no Rio de Janeiro em 1837.

9 Henriqueta Galeno ocupou o cargo de professora do Liceu entre os anos 1922 e 1929; ministrou a disciplina história do Brasil. Era educadora, literata e poetiza. Filha de Juvenal Galeno, teve em sua vida acesso ao movimento cultural e literário por intermédio de seu pai - cuja vontade era de que sua filha "se preocupasse apenas em difundir a cultura e os movimentos ligados ao regionalismo cearense e não que se dedicasse tanto à militância feminista, como fez" (Oliveira, C. S., 2007, p. 95). Bacharelou-se em ciências e letras e foi aluna do Liceu do Ceará. Graduou-se pela Faculdade de Direito do Ceará em 1918 e foi convidada pelo então presidente do Estado, Dr. João Tomé, a ser promotora da Capital. Seu pai, Juvenal, fez com que recusasse; então Henriqueta foi nomeada inspetora do ensino estadual. 
de o homem conseguir trabalhar melhor o conteúdo e a ordem, pois apenas a "consciência da mulher, sua paciência e porventura melhor compreensão da natureza moral da criança, não supriam a sua 'falta de sistema". O documento justifica o fato de que, nas escolas elementares, elas se saíam bem por que o objeto de ensino era claro e fácil: letras e algarismos. Assim era praticamente impossível que as professoras complicassem a tarefa de aprender. (idem, p. 93)

Henriqueta Galeno, além de conseguir se inserir em um espaço educacional fechado à presença feminina, também obteve destaque no campo literário cearense, tão hostil à participação de mulheres: foi nomeada imortal da Academia Cearense de Letras (ACL) em 1951. A "desvantagem literária" feminina pode ser compreendida também por meio do discurso oficial da época, contido no Relatório do governo do Ceará de 1919 (apud Oliveira, J. C., 2007), o qual, ao se referir sobre a atuação das mulheres como professoras de gramática, afirma que "Onde a paixão substitui o pensamento, elas se avantajam algumas vezes ao homem. Mas já fizeram baixar singularmente o nível literário na Inglaterra e na América do Norte, desde que se apoderaram desse domínio" (idem, ibidem).

De acordo com a lei n. 743, de 22 de outubro de 1833 (APEC, IP. PP., p.11), que regia a instrução pública no Ceará, todas as mulheres que se candidatassem a uma vaga no magistério deveriam comprovar o estado civil: se fossem casadas, apresentariam a certidão de casamento; se fossem viúvas, deveriam apresentar a certidão de óbito do marido; e, se viessem a se separar, deveriam justificar os motivos da separação. As mulheres solteiras, por sua vez, somente poderiam concorrer à vaga se fossem maiores de 25 anos, salvo se ensinassem na casa de seus pais, pois não era conveniente que moças com menos de 25 anos ficassem transitando pelas "localidades". Mas quem oficialmente poderia ser professora de primeiras letras? Seriam "aquelas senhoras que por sua honestidade, prudência e conhecimentos se mostrarem dignas de tal ensino, compreendendo também o de coser e bordar" (Louro, 2004, p. 444).

Outra dimensão do trabalho docente deve ser levada em consideração, um mecanismo mais sutil de discriminação: embora a lei da instrução pública determinasse que homens e mulheres professores tivessem igual salário, "a diferenciação curricular acabava por representar uma diferenciação salarial, pois a inclusão da geometria no ensino dos meninos implicava outro nível de remuneração no futuro - que só seria usufruído pelos professores" (idem, ibidem).

Naquele período, houve uma aceitação da presença de mulheres no exercício da função de professora de primeiras letras, porém pesava sobre ela uma forte vigilância no que dizia respeito à sua conduta moral e religiosa, pois se vivia um momento em que a Igreja católica ${ }^{10}$ penetrava fortemente no campo educacional. No Índice da Instrução Pública do Arquivo Público do Estado do Ceará (APEC),

10 Zaíra Ary (2000) traz em sua obra a discussão sobre como o imaginário católico interferiu na consolidação da sociedade ocidental, pondo a mulher numa posição de inferioridade, até mesmo intelectual, em relação ao homem. 
podem ser encontrados vários registros de professoras solicitando à Secretaria de Educação e Cultura do Estado do Ceará catecismos para a educação religiosa de seus alunos e alunas, que eram ensinados separadamente. ${ }^{11}$

A partir de 1846, com a lei n. 390, foi estabelecida a criação de escolas de primeiras letras para o sexo feminino no estado do Ceará. Nesse espaço se desenvolviam atividades específicas para esse sexo, efetivando-se uma educação fortemente voltada para o âmbito doméstico, ensinando às alunas a exercerem as funções que lhes cabiam, de acordo com o discurso que naturalizava o destino de esposa e mãe.

De acordo com carta enviada por uma professora de Aracati, em 1847, para Thomaz Pompêo de Souza Brasil, diretor do Liceu e também diretor-geral da Instrução Pública (vale lembrar que naquele período o colégio Liceu era a instituição educacional mais importante do estado), percebe-se como na educação feminina eram realizadas atividades que reforçavam e reproduziam um papel específico exigido para as mulheres:

o methodo que tenho usado, he dar aula as sete horas da manhã, até as onze e meia, e das duas da tarde à seis; e durante este tempo as alunnas lêem, escrevem, contão, cosem, bordão, resão a doutrina nas quartas e sábados. São estas as matérias que ensino $[s i c]$. (APEC, 1847)

Nesse contexto de uma educação dividida sexualmente, as exigências que pesavam sobre mulheres e homens professores eram de ordem bem específica. Ambos, no que se refere à documentação para a contratação docente, tinham de apresentar atestado de conduta moral e civil expedido por seus respectivos párocos, pois o respeito para com a doutrina e a prática católica tinha um peso considerável. Porém, socialmente, pesavam sobre cada sexo exigências diferenciadas. Isso pode ser percebido nas "queixas e denúncias" que eram feitas a respeito dos professores e professoras.

As queixas e denúncias contra docentes eram realizadas por meio de cartas, ofícios, relatórios, e direcionados ao diretor-geral da Instrução Pública do Ceará. Alguns desses documentos foram escritos por membros de famílias influentes em sua "localidade", por outros profissionais da educação, ou ainda pelos párocos representantes locais da Igreja católica. Desse modo, no município de Jardim, em 1859, por meio de carta escrita por um "pai de família", a professora Joanna Henriqueta de Almeida foi acusada de não ter conduta moral e religiosa adequada para a profissão,

11 A coeducação dos sexos foi objeto de debate durante o século XIX. O movimento feminista internacional, que já nos oitocentos ganhava força na Europa e Estados Unidos, contribuiu sobremaneira para o processo de redefinição dos discursos que afirmavam a menor capacidade intelectual feminina. Nessas discussões se estabeleciam uma disputa entre a Igreja católica, fervorosa opositora ao regime de coeducação, e os liberais republicanos que defendiam uma escola laica e universal. Na educação pública do Brasil do século XIX, as "salas mistas" demoraram mais a se consolidarem que nas instituições privadas, que foram as primeiras a adotar o regime de coeducação dos sexos, crescentemente praticado nos Estados Unidos e na França. 
"pois vivia com a mãe, que era separada, e seus pais não tinham boa conduta moral" (APEC, 1859). Em Pereiro, 1866, também por meio de carta, foi feita uma queixa contra a professora Maria Ignácia Franco do Nascimento, na qual ela foi acusada de manter relações ilícitas com o capitão da Guarda Nacional daquela vila, tendo rejeitado uma criança que teria dado à luz (APEC, 1866).

No ano de 1874, foi publicada pelo jornal Futuro, de circulação local, uma acusação contra a professora Amélia Baptista, de vila da União Cândida: ter um filho sem ser casada ou viúva, fruto de uma "conduta irregular". Foi denunciado que Amélia mantinha "relações" com o genitor da criança "causando indignação de muitos pais de família”. A professora enviou ao diretor-geral da Instrução Pública documentos que contestavam a acusação, como comprovante de boa conduta moral e religiosa emitido pela paróquia local e comprovante de casamento, bem como questionários feitos às testemunhas sobre sua conduta na vila. Tais documentações não foram suficientes para resguardar seu cargo de professora, pois, após investigação realizada pela Inspetoria Litterária da Comarca de Aracaty, foi confirmado que, de fato, Amélia havia engravidado em período anterior a seu casamento.

Contra Anna Verina Ribeiro, vila de Soure, em 1875, por meio de carta escrita por pai de um de seus alunos, foi feita a acusação de "estar grávida sendo viúva". Em resposta, Anna afirmou que teria sido "seduzida por seu vizinho com promessas de casamento". A professora foi suspensa por seis meses, sendo processada pelo Conselho Literário e, enfim, demitida (APEC, 1875).

É relevante dizer que, ao inventariar os documentos, pude constatar que poucas queixas e processos contra professores do sexo masculino envolviam questões de vida familiar e sexual. Reclamava-se, na maioria das vezes, da conduta profissional, como nos casos em que os professores exerciam outro ofício, pois a docência obrigatoriamente exigia dedicação exclusiva. Em contrapartida, as poucas queixas relacionadas à moral falavam da vida religiosa desatenciosa dos professores, ou do envolvimento com jogos etc. Também há registros que se fundamentaram em condutas políticas impróprias dos professores que se voltavam contra a Igreja, na pessoa do padre.

Nas queixas e processos, quando se citava a vida sexual dos professores, a referência era aos casos em que haviam "deflorado" alguma "moça de família", sendo essa conduta questionada por terem transgredido normas relativas ao comportamento das moças "casadouras" pertencentes a famílias tradicionais. Já no que se refere às professoras, há poucos registros de queixas fundamentadas em questões exclusivamente profissionais.

A conduta moral e religiosa dessas mulheres ocupava um lugar de fato privilegiado, ao passo que, muitas vezes, sua competência e compromisso com o lecionar eram simplesmente desconsiderados se a conduta na vida íntima era considerada inapropriada. Esse aspecto pode ser constatado na leitura de uma carta enviada pela Inspetoria Litterária da Comarca de Aracaty para o diretor-geral da Instrução Pública, em 1874, após averiguarem a procedência da queixa feita contra a professora Cândida Amélia Baptista, que levou à sua demissão: 
[...] acusa a professora daquela villa D. Cândida Amélia Baptista de irregularidade de conduta, tendo dado a luz ultimamente a uma menina sem ter sido casada nem viúva [...] Compreendendo de quanta gravidade era aquella acusação, pela desmoralização que acarretava a instrução, que na moralidade do professor deve encontrar mais uma fonte de vida e animação, entendi de necessidade dirigir-me aquella villa [...] $\mathrm{E}$ ali, sanção que sofria a professora $\mathrm{D}$. Cândida nada tinha de caluniosa. [...] Profundamente lastimo que seja esta a verdade, pois D. Cândida por sua intelligência e aptidão para o ensino, é uma destas professoras que muito fazem ganhar a instrução [sic]. (APEC, 1874)

Assim como ocorreu com inúmeras outras mulheres, na trajetória de Cândida Amélia Baptista, sua inteligência e empenho no ensino não foram suficientes para lhe garantir a permanência no cargo de professora de primeiras letras. Por serem consideradas moralmente inferiores aos homens, pesava na vida das professoras uma vigilância e controle muito maiores.

\section{OUTROS LUGARES, SEMELHANTES DISPUTAS: A INSERÇÃO FEMININA EM ESPAÇOS PENSADOS PARA HOMENS "DE CIÊNCIA E DE LETRAS"}

Fundado em 1887, o Instituto do Ceará (Histórico, Geográfico e Antropológico) surge pela iniciativa de onze sócios-fundadores, entre eles Barão de Studart, Juvenal Galeno e Antônio Bezerra de Menezes, todos homens de ciência e de prestígio no estado.

Motivados pelo desejo de tornar conhecidas a história e a geografia da província, onze vultos da sociedade cearense empreenderam árdua tarefa a fim de fazer do Instituto referência nacional para a propagação de pesquisas que legitimasse a formação de sua história. ${ }^{12}$

Somente em 1930, quase cinquenta anos após a criação do instituto, entra em cena a primeira mulher, Júlia de Vasconcelos, cujo pai havia sido um dos fundadores dessa instituição e da ACL, Antônio Augusto de Vasconcelos.

Júlia, pioneira entre os varões, foi recebida em meio a contestações que não se vinculavam apenas a uma suposta incapacidade intelectual, mas ao fato de ser ela uma mulher. $\mathrm{Na}$ ocasião de sua posse, Antônio Theodorico da Costa ${ }^{13}$ reafirma

12 As informações relativas à história do Instituto do Ceará (Histórico, Geográfico e Antropológico) podem ser encontradas em seu site oficial. Nesse sítio estão disponibilizadas as digitalizações das revistas do instituto, com publicações desde o século XIX. Disponível em: <http://www.institutodoceara.org.br>. Acesso em: 23 nov. 2010.

13 Antônio Theodorico da Costa foi autor do "Discurso a ser entregue a Bandeira Nacional ao Tiro 309 em nome da Mulher Cearense", publicado pelo Instituto do Ceará em 1917. Em tom ufanista, afirma que é "dádiva espontânea do coração da 
o "seu modo de pensar contrário à coparticipação do elemento feminino em certames científicos" dizendo: "Senhora, neste exato momento de vossa posse, lembrai sempre que um membro daquela assembleia se opusera ao vosso ingresso no seio do instituto" (Revista do Instituto do Ceará, 1931 apud Camurça, 1968).

Passado o dia de sua posse, nunca mais Júlia de Vasconcelos pôs os pés na sede do Instituto do Ceará. Contudo, fez-se notada a sua presença na revista da instituição, onde publicou seus trabalhos. Quando precisou mudar-se para o Sul do país por questões familiares, passou de sócia efetiva para sócia honorária. Antes de seu ingresso no instituto, Júlia já havia elaborado relevantes estudos na área da geografia e da história. Além de sua contribuição científica, também colaborou efetivamente com a imprensa do Ceará (Camurça, 1968).

Júlia de Vasconcelos faleceu em 1950, tendo como sucessora Alba Valdez, de atitude diferenciada, envolvida fortemente com as causas feministas, "artista da gramática e do estilo, exímia no manejo da língua pátria, profunda conhecedora dos mais recônditos vicejos da língua portuguesa, expressa sua arte em páginas de serviço às letras e à mulher" (idem, p. 185). Alba Valdez também se destacou na imprensa cearense. Em 1922, ingressou na ACL, a única mulher entre os acadêmicos de então. No âmbito político, instalou e presidiu a Liga Feminista Cearense.

Além do Instituto do Ceará, merece destaque a "Academia Cearense", que, assim como o referido instituto, foi pensada e fundada por uma elite intelectual masculina. Foi criada em 15 de agosto de 1894, inspirada na Academia de Ciências de Lisboa, com os seguintes fins:

a) Examinar e emittir parecer sobre theorias, problemas e questões da actualidade; b) acompanhar o movimento intelectual dos povos cultos, adaptando ao nosso meio as idéias, que parecerem mais úteis ao seu melhoramento e ao engrandecimento do espirito humano; c) estabelecer palestras e conferências; d) trabalhar pelo levantamento da instrucção, maximé do ensino profissional [sic]. ${ }^{14}$

A fundação da academia se deu por vinte e oito "homens de letras". ${ }^{15}$ Entre os fundadores, nenhuma mulher. Leonardo Mota, no ano LIV da Revista do

mulher cearense a traduzir os seus alentos, affectos e amores às generosidades e ensinamentos da juventude [sic]", relegitimando a associação entre o amor feminino e a docência. Theodorico chega a construir nesse discurso uma associação entre a Bandeira Nacional e a mulher. Referindo-se às cores da bandeira, diz: "é branca, e é a pureza da mulher brasileira, seus encantos, suas graças, sua pulchra candura [sic]" (Costa, 1917, p. 226). Disponível em: <http://www.ceara.pro.br/Instituto-site/Rev-apresentacao/ RevPorAnoHTML/1917indice.html>. Acesso em: 24 set. 2009.

14 Trecho retirado do site da ACL, no qual podem ser encontradas informações sobre a história de atuação da academia no estado do Ceará. Disponível em: <http://www. ceara.pro.br/ACL/fundadores/fundadores.html>. Acesso em: 20 abr. 2011.

15 Adolfo Frederico Luna Freire; Alcântara Bilhar; Álvaro de Alencar; Álvaro Mendes; Antônio Bezerra de Meneses; Antonino Fontenele; Antônio Augusto de Vasconcelos; Antônio Theodorico Filho; Benedito Sidou; Drumond da Costa; Eduardo Salgado; Eduardo Studart; Farias Brito; Francisco Alves Lima; Franco Rabelo; Guilherme 
Instituto do Ceará, afirma que, em 1922, apenas oito desses homens permaneciam na capital, os outros já haviam falecido ou se achavam ausentes por outros motivos. Por encontrar-se esvaziada, resolveu-se então reorganizá-la sob nova denominação: “Academia Cearense de Letras". Nesse contexto de reorganização, eleva-se para quarenta o número de sócios, ocasião em que entra Alba Valdez.

Em 1923, com a morte de Justiniano de Serpa, então presidente, as reuniões da academia foram suspensas, sendo retomadas apenas em 1930. Nesse período de retomada dos encontros literários, Alba Valdez não foi convidada para ser membro integrante da academia, provavelmente por ainda haver resistência à presença feminina nesse espaço pensado por homens e para homens. Entretanto, em 1937, Alba candidatou-se novamente e foi eleita. Em 1951, ingressa na academia Henriqueta Galeno, a segunda mulher associada. Conforme mencionado anteriormente, Henriqueta foi uma mulher que conseguiu adentrar em recintos tidos como masculinos, a única mulher professora do Liceu do Ceará até 1930.

De acordo com as estatísticas disponibilizadas pela ACL, ao longo dos 117 anos de sua existência, somente 11 mulheres conseguiram se inserir num universo de 178 acadêmicos, constituindo 6,2\% do total.

Após a entrada de Henriqueta Galeno, em 1960 entra Cândida Galeno, sobrinha de Henriqueta; em 1988, Noemi Elisa Aderaldo assume a cadeira 33; em 1990 é eleita Marly Vasconcelos; em 1994 entram Raquel de Queiroz e Beatriz Alcântara; em 1996 assume a cadeira 21 a escritora Regine Limaverde; Ângela Gutiérrez ingressa em 1997; Giselda Medeiros no ano 2000; e Natércia Campos em 2002.

Vale mencionar que a primeira mulher a fazer parte da Academia Brasileira de Letras (ABL) foi uma cearense, Raquel de Queiroz, em 1977. Desde a sua fundação, em 1897, somente depois de passados oitenta anos, a presença feminina foi aceita entre os acadêmicos. Naquele período, a aceitação de Raquel pela ABL causou certa euforia entre os seguimentos feministas que denunciavam a marginalização feminina no cânone literário.

Raquel de Queiroz construiu em sua trajetória uma aproximação com a esquerda política nacional, inserindo-se, até mesmo, nos fins da década de 1920, no Bloco Operário Camponês em Fortaleza, o primeiro núcleo do Partido Comunista. Entretanto, a escritora, para o desapontamento das feministas, não quis se aproximar do movimento e não queria ser identificada como uma escritora feminista, ou mesmo que sua obra fosse classificada como uma literatura tipicamente feminina. Ao entrar na ABL, declara: "Eu não entrei para a Academia por ser mulher. Entrei, porque, independentemente disso, tenho uma obra. Tenho amigos queridos aqui dentro.

Studart; Henrique Théberge; José Fontenele; José Carlos Júnior; José de Barcelos; Justiniano de Serpa; padre Valdevino Nogueira; Pedro de Queirós; Raimundo Arruda; Tomás Pompeu de Sousa Brasil (primeiro presidente); Waldemiro Cavalcante; e Virgílio Augusto de Morais. 
Quase todos os meus amigos são homens, eu não confio muito nas mulheres”. Em entrevista concedida a Haroldo Bruno (1977, p. 121 apud Ferreira, 2003, p. 89), diz:

Nunca fui feminista... tudo é gente, tudo é criatura. Claro que acho que as mulheres, nas sociedades mais atrasadas, têm a vida mais dura e mais estreita que a dos homens; mas isso são contingências do ambiente social no seu todo, e não um propósito especial de discriminação contra a mulher. Aliás, quem primeiro discriminou foi Deus, Nosso Senhor...

Esse posicionamento de Raquel, de acordo com Ferreira (idem), pode ser compreendido como uma estratégia discursiva, na qual a renúncia ao feminino está intimamente relacionada com sua manobra de sobrevivência e reconhecimento no seio do campo literário. Ou seja, "considerando o caráter negativo então aferido às obras 'preconceituosamente femininas' (Bruno, 17), ela nega tal caráter para manter seu espaço e respeitabilidade como escritora” (Ferreira, 2003, p. 89).

Somente mais tarde, em 1994, Raquel de Queiroz ingressou na ACL, por ocasião das festividades em comemoração ao primeiro centenário da instituição. ${ }^{16}$

Essas pioneiras nas instituições de ciências e letras no Ceará merecem destaque não por serem excepcionais, destoantes entre as outras, mas por terem sido reconhecidas em sua atuação no campo científico e literário cearense, enquanto muitas permaneceram na penumbra. Júlia de Vasconcelos, Alba Valdez, Henriqueta Galeno, Raquel de Queiroz são precursoras de uma série de outras conquistas que puderam ser observadas, porém, resguardada a importância dessas mulheres, elas aqui representam alguns entre tantos outros nomes que poderiam ser citados.

No entanto, mais importante que mencioná-las, é ter a compreensão dos discursos e práticas que delineavam o campo científico. Nesse sentido, de acordo com Mariza Corrêa (2003), conhecer a atuação contextualizada de algumas de nossas antepassadas nos ajuda muito a compreender as relações de poder que ainda permeiam a prática científica na qual as mulheres se inserem na contemporaneidade.

\section{CONSIDERAÇÕES FINAIS - A VISÃO PARCIAL DAS CIÊNCIAS}

Em que o olhar para o campo educacional e literário interessa para a compreensão das ciências numa perspectiva de gênero? Conhecer os discursos hegemônicos na educação e na literatura durante os séculos XVIII e XIX pôs-se como

16 Para ingressar na ACL, há um processo de eleição interna, quando os candidatos às cadeiras disponíveis - em decorrência do falecimento do antigo ocupante - procuram todos os membros da academia para assim obterem seus votos. Raquel, desde 1977, já era imortal da $\mathrm{ABL}$, contudo não poderia ser aceita pela ACL em virtude do regulamento que firmava a condição para que se ingressasse como membro: teria de ser cearense e residir no estado do Ceará. Raquel morava no Rio de Janeiro. Para que a escritora pudesse participar da ACL, o regulamento foi então modificado, sendo inserinda uma cláusula: "exceto se pertencer à Academia Brasileira de Letras". 
uma indispensável tarefa na busca pelo desvendamento das práticas que envolveram as mulheres nas ciências do Ceará antes do século XX, quando surgiu a primeira universidade local.

No campo educacional, inicialmente, a inserção feminina se deu como "professoras de primeiras letras". Essas trabalhadoras docentes foram acolhidas num ensino primário marcado pela racionalidade dicotômica ocidental, para a qual as contraposições sujeito/objeto, cultura/natureza, razão/emoção são análogas à contraposição masculino/feminino. As mulheres eram percebidas como mais intuitivas (mais próximas da natureza e distantes da cultura) e menos racionais que os homens. Exercer o magistério primário legitimava-se pela ideia de que, também na escola, as crianças precisavam do "amor maternal".

Podemos observar que, até o início do século XX, era hegemônica a ideia de que as mulheres deveriam receber uma educação diferenciada, que lhes preparassem para o papel social de mãe e esposa. Assim, as ciências e os espaços canônicos das letras e da produção de conhecimento foram forjados como lugares hostis à presença feminina, como podemos perceber na realidade do Instituto do Ceará (Histórico, Geográfico e Antropológico) e da ACL.

Mas quem foram essas mulheres professoras de primeiras letras durante o século XIX? Que mulheres conseguiram ser pioneiras nos espaços canônicos das ciências e das letras? Predominantemente, essas pioneiras eram mulheres brancas, pertencentes a classes sociais abastadas e a famílias cujos homens faziam parte da elite intelectual e política cearense. Também as professoras de primeiras letras do século XIX, mesmo inseridas num trabalho docente precário, eram provenientes de núcleos familiares com relativo destaque econômico e cultural em seu respectivo território.

Eram mulheres, pode-se dizer, privilegiadas, pois que, até as primeiras décadas do século XX, era perceptível na educação pública uma discriminação de classe que atingia também os homens. $\mathrm{O}$ campo educacional refletia a lógica da reprodução das desigualdades sociais. Assim, o âmbito escolar foi sendo consolidado por práticas educativas direcionadas às elites, de acordo com o que revelam Adelaide Gonçalves e Allyson Bruno (2002, p. 73):

O filho do operário, quando chega à idade de ir para a escola, mandam-no para a oficina: em vez do livro, dão-lhe a ferramenta do ofício. É mais uma vítima que vai ser devorada pelo Moloch do capitalismo implacável, [...] é se ver pelas fábricas, crianças pálidas, linfáticas, minadas de clorose, organismos que se preparam para a tuberculose $[\ldots]$.

No Ceará, somente a partir da década de 1930 é que se percebe o esforço político de ampliar o acesso à educação pública para a classe operária, discutindose, até mesmo, a importância da existência de escolas voltadas para as populações rurais (Cavalcanti, 2000). Todavia, entre esses avanços, a discriminação de gênero permanece, visto que se recomendava como indispensável "uma educação doméstica criteriosamente orientada" para as meninas (idem, p. 205). 
A realidade particular do Ceará deve ser contextualizada na ambiência mais ampla da modernidade ocidental demarcada pelo sexismo. As práticas discriminatórias eram resguardadas em nome da autoridade científica. Visceralmente imbricados ao campo científico, os campos educacional e literário legitimavam a lógica da divisão sexual do papéis sociais pensados para cada sexo. Conforme já mencionado, o pensamento de Jean-Jacques Rousseau, reconhecido "profeta da igualdade" e "pai da pedagogia moderna”, é um clássico exemplo sexista:

O homem diz o que sabe, a mulher diz o que o agrada; para falar, um precisa de conhecimento, a outra de gosto; [...] Todas as reflexões das mulheres naquilo que não diz respeito imediatamente a seus deveres devem visar ao estudo dos homens ou aos conhecimentos agradáveis [...]; elas têm tampouco justeza e atenção bastantes para serem bem-sucedidas nas ciências exatas; e, no que se refere aos conhecimentos físicos, cabe ao mais ativo dos dois sexos [...]. Cabe às mulheres encontrar, por assim dizer, a moral experimental, e a nós reduzi-la a sistema. A mulher tem mais espírito, e o homem tem mais gênio, a mulher observa e o homem raciocina; dessa configuração resultam a luz mais clara e a ciência mais completa que o espírito humano possa adquirir por si mesmo, o mais seguro conhecimento. (Rousseau, 2004, p. 545)

Foi a reiteração de discursos como o rousseauniano que envolveu a inserção de mulheres em espaços pensados para homens. Portanto, se neste artigo foram citados alguns nomes de mulheres consideradas "pioneiras", isso não se deu no intuito de retornar ao projeto "mulheres notáveis", que pretendia restaurar a voz de mulheres consideradas importantes na história (Harding, 1996). Citar o nome dessas "pioneiras" significa a intenção de privilegiar o diálogo fundamental e constante entre indivíduo e sociedade; no caso, entre mulheres e ciências no Ceará. Mulheres que experienciaram uma trajetória profissional imersas em instituições educacionais, literárias e científicas herdeiras da racionalidade moderna ocidental, que muitas vezes se põe a serviço de iniciativas classistas, racistas, sexistas e homofóbicas (idem).

Ademais, para além da incontestável contribuição educacional, científica e literária dessas mulheres, as conquistas femininas na produção de conhecimento científico no Ceará devem ser dialogadas com as reivindicações dos movimentos feministas que ultrapassaram o sufragismo, percebendo que no direito à educação igualitária residia uma maior possibilidade de construir a tão sonhada "emancipação feminina” (Matias dos Santos, 2004). É relevante dizer que o feminismo no Ceará, embora tenha suas especificidades, deve ser percebido como parte de uma articulação que vinha se construindo, em âmbito internacional, desde a Revolução Francesa (Scott, 2002), como um contraponto ao sexismo na modernidade.

É indispensável saber que as resistências à participação feminina nos espaços aqui mencionados não se traduzem em experiências isoladas e únicas, mas como parte do processo de construção das ciências ocidentais em sua totalidade: as mulheres foram produtoras de conhecimento, e, contudo, o mais das vezes, sua 
presença e produções intelectuais foram desconsideradas, invisibilizadas ou, melhor, produzidas discursivamente como inexistentes (Santos, 2007).

Por fim, ressalto que as narrativas aqui construídas referem-se a lugares, tempos e sujeitos específicos. São narrativas possibilitadas por alguns "fragmentos de história", os quais podem ter sua relevância calcada na "vantagem epistemológica de uma perspectiva parcial" (Haraway, 1995), tentando perceber as ciências por meio da sua "multiplicidade de visões". E mais: este escrito não se propõe como uma percepção pronta e acabada das ciências, da literatura ou da educação, visto que a visão parcial nunca se encerra.

\section{REFERÊNCIAS}

Adelman, Miriam. Um lugar ao sol? A teoria feminista e seu lugar no campo das ciências sociais. In: Lago, Mara Coelho de Souza; Grossi, Miriam Pillar; Rocha, Cristina Tavares da Costa. Interdisciplinaridade em diálogos de gênero: teorias, sexualidades, religiões. Florianópolis: Editora Mulheres, 2004. p. 165-175.

AlmeidA, Jane Soares. Coeducação ou classes mistas? Indícios para a historiografia escolar (São Paulo - 1870-1930). Revista Brasileira de Estudos Pedagógicos, Brasília: INEP, v. 86, n. 213/214, p. 64-78, maio/dez. 2005.

APEC. Índice da Instrução Pública. BR APEC, IP.PP. p. 11-ind.

Aristoteles. Metafísica. Tradução direta do grego de Vincenzo Coceo. São Paulo: Editor Victor Civita, 1984. p. 8-43.

Arquivo Público do Estado do Ceará. Carta [de uma professora para Thomaz Pompêo de Souza Brasil, diretor-geral da Instrução Pública]. Atividades na escola para sexo feminino. Aracati: APEC, 1847. BR APEC, IP.PP.CO, RE.28-37.

. Carta [de um pai de família]. Representação contra a professora Joanna Henriqueta de Almeida. Jardim: APEC, 1859. BR APEC, IP.CO.QX.1/5.

. Carta. Queixa contra a professora Maria Ignácia Franco do Nascimento.Pereiro: APEC, 1866. BR APEC IP. CO, QX. 1/11.

. Carta. Queixa contra a professora da vila da União Cândida, Amélia Baptista. Aracati: APEC, 1874. BR APEC, IP, CO, QX. 1/40.

Carta. Queixa contra professora Anna Verina Ribeiro, por achar-se grávida sendo viúva. Soure: APEC, 1875. BR APEC, IP.CO, QX. 1/49.

Ary, Zaíra. Masculino e feminino no imaginário católico. São Paulo: Annablume; Fortaleza: Secult, 2000.

Bourdieu, Pierre. Os usos sociais da ciência: por uma sociologia clínica do campo científico. Tradução de Denice Barbaba Catani. São Paulo: Editora UNESP, 2004.

.A dominação masculina. 4.ed. Tradução de Maria Helena Kühner. Rio de Janeiro: Bertrand Brasil, 2005.

. O poder simbólico. Rio de Janeiro: Bertrand Brasil, 2007. 
Brasil. (Período Imperial). Lei de 15 de outubro de 1827. Manda criar escolas de primeiras letras em todas as cidades, vilas e lugares mais populosos do Império. Coleção das Leis do Brasil, 15 out. 1827

Bruno, Haroldo. Rachel de Queiroz. Rio de Janeiro: Livraria Editora Cátedra, Instituto Nacional do Livro, Ministério da Educação e Cultura, 1977.

Camurça, Zélia de Sá Viana. A presença da mulher, a educação da mulher. Revista do Instituto do Ceará, Fortaleza: Instituto do Ceará, p. 183-210,1968. Disponível em: <http:// www.ceara.pro.br/Instituto-site/Rev-apresentacao/RevPorAno/1968/1968-APresencad aMulhereaEducacaodaMulher.pdf>. Acesso em: 24 set. 2009.

Castelo, Plácido Aderaldo. História da instrução e da educação do Ceará. Revista do Instituto do Ceará, Fortaleza: Instituto do Ceará, p. 52-70, 1943. Disponível em: <http:// www.ceara.pro.br/Instituto-site/Rev-apresentacao/RevPorAno/1943/1943-Historia_da_ Instrucao_e_da_Educacao_do_Ceara.pdf >. Acesso em: 23 set. 2009.

Cavalcantı, Maria Juraci Maia. Algumas indagações sobre o silêncio em torno da $6^{\mathrm{a}}$ Conferência Nacional de Educação. História da Educação, Pelotas: UFPEL, n. 8, p. 193209, set. 2000. Disponível em <http://seer.ufrgs.br/asphe/article/view/30165>. Acesso em: 9 maio 2013.

Ceará (Província). Lei n. 390, de 5 de setembro de 1846. [Trata da criação de escolas de primeiras letras para o sexo feminino no estado do Ceará]. Documentos - Revista do Arquivo Público do Ceará: história e educação, Fortaleza: APEC, n. 2, p. 174-176, 2006.

Chassot, Attico Inácio. A ciência é masculina? É sim, senhora! São Leopoldo: Editora Unisinos, 2003. (Coleção Aldus 16)

CorrêA, Mariza. Antropólogas e antropologia. Belo Horizonte: Editora da UFMG, 2003. Costa, Antônio Theodorico. Discurso ao ser entregue à Bandeira Nacional ao Tiro 309 em nome da mulher cearense. Revista do Instituto do Ceará, Fortaleza: Instituto do Ceará, p. 225-228, 1917. Disponível em: <http://portal.ceara.pro.br/index. php?option=com_content\&view=article\&id=33794:1917-discurso-ao-ser-entregue-abandeira\&catid=469\&Itemid=101 >. Acesso em: maio 2014.

Dur кheim, Émile. Da divisão do trabalho social. 3. ed. Lisboa: Editorial Presença, 1989. Falci, Miridan Knox. Mulheres do sertão nordestino. In: Del Priore, Mary (Org.). História das mulheres no Brasil. 7. ed. São Paulo: Contexto, 2004. p. 241-277.

Ferreira, Débora Ribeiro de Sena. Pilares narrativos: a construção do eu e da nação na prosa de oito romancistas brasileiras. Florianópolis: Editora Mulheres, 2003.

Ginzburg, Carlo. Olhos de madeira: nove reflexões sobre a distância. São Paulo: Companhia das Letras, 2001. p. 15-41.

Gonçalves, Adelaide; Bruno, Allyson. Libertários: educação da solidariedade e educação da revolta. Verve, São Paulo: PUC, n. 2, p. 65-87, 2002. Disponível em: <revistas.pucsp. br/index.php/verve/article/viewFile/4612/3203>. Acesso em: 8 maio 2013.

Guibernau, Montserrat. Nacionalismos: o estado nacional e o nacionalismo no século XX. Tradução de Mauro Gama e Cláudia Martinelli Gama. Rio de Janeiro: Jorge Zahar, 1997. 
Haraway, Donna. Saberes localizados: a questão da ciência para o feminismo e o privilégio da perspectiva parcial. Tradução de Mariza Corrêa. Cadernos Pagu, Campinas: UNICAMP, n. 5, p. 7-41, 1995.

. Situated knowledge: the science question in feminism and the privilege of partial perspective. In: LEDERMAN, Muriel; BARTSCH, Ingrid. The gender and science reader. London/New York: Routledge, 2001. p. 196-188.

Harding, Sandra. Ciencia y feminismo. Traducción de Pablo Manzano. Madrid: Ediciones Morata, 1996. (Colección Psicología Manuales)

Heller, Agnes. O cotidiano e a história. 8. ed. São Paulo: Paz e Terra, 2008.

Hirata, Helena. Nova divisão sexual do trabalho? Um olhar voltado para a empresa e a sociedade. São Paulo: Boitempo Editorial, 2002.

KeHL, Maria Rita. A minima diferença: masculino e feminino na cultura. Rio de Janeiro: Imago, 1996.

Lopes, Maria Margareth. Mulheres e ciências no Brasil: uma história a ser escrita. In: Sedeño, Eulália Pérez; Cortijo, Paloma Alcalá (Orgs.). Ciencia y género. Madrid: Universidad Complutense de Madrid, 2001. p. 53-68.

Louro, Guacira Lopes. Mulheres na sala de aula. In: Del Priore, Mary (Org.). História das mulheres no Brasil. 7. ed. São Paulo: Contexto, 2004. p. 443-481.

Madeira, Maria das Graças de Loiola. A pedagogia cristã para mulheres no sertão cearense (1862-1876). In: Seminário Internacional Educação Intercultural, Gênero e Movimentos Sociais: identidade, diferença e mediações, 2., 1997, Ilha de Santa Catarina. Anais... Ilha de Santa Catarina: Universidade Federal de Santa Catarina, 1997. Disponível em: <www.rizoma.ufsc.br/.../Maria\%20das\%20Graças\%20 de\%20Loiola\%20Madeira.UFC.doc>. Acesso em: 20 fev. 2010.

Matias dos Santos, Vívian. Gênero e pesquisa: caminhos cruzados. Uma abordagem comparativa da participação de mulheres e homens na produção científica e tecnológica da Universidade Estadual do Ceará. 2004. Monografia (Graduação em Serviço Social) - Universidade Estadual do Ceará, Fortaleza, 2004.

Ruptura dos códigos de gênero ou mecanismos sutis de discriminação? Mulheres e homens na política de fomento à ciência e tecnologia: um estudo da Fundação Cearense de Apoio ao Desenvolvimento Científico e Tecnológico (FUNCAP). 2007. Dissertação (Mestrado Acadêmico em Políticas Públicas e Sociedade) - Universidade Estadual do Ceará, Fortaleza, 2007.

Uma abordagem sociológica da sociologia: a ciência como campo. Revista Espaço Acadêmico, Maringá: UEM, n. 133, p. 137-144, jul. 2012. Disponível em: <http://www. periodicos.uem.br/ojs/index.php/EspacoAcademico/article/view/15123>. Acesso em: 8 maio 2013.

Morais, Vinícius de. Livro de sonetos. São Paulo: Companhia das Letras, 1991.

Oliveira, Antônio de Almeida. O ensino público. Brasília: Senado Federal, Conselho Editorial, 2003. 
Oliveira, Carla Silvino. Cidade (in)salubre: ideias e práticas médicas em Fortaleza (1838-1853). 2007. Dissertação (Mestrado em História Social) - Universidade Federal do Ceará, Fortaleza, 2007.

Oliveira, Joyce Carneiro. Entre guerras e as reformas: o ensino secundário cearense (1918-1930). Dissertação (Mestrado em Educação Brasileira) - Universidade Federal do Ceará, Fortaleza, 2007.

Puleo, Alícia Helda. Filosofía, género y pensamiento crítico. Universidad de Valladolid, 2002. (Colección “Acceso al Saber”, Serie Filosofía)

Ribeiro, Maria Luisa Santos. História da educação brasileira: a organização escolar. 16. ed. Campinas: Autores Associados, 2000. (Coleção Memória da Educação)

Rousseau, Jean-Jacques. Emílio ou da educação. 3. ed. São Paulo: Martins Fontes, 2004. (Coleção Paideia)

SAntos, Boaventura de Sousa. Para uma sociologia das ausências e uma sociologia das emergências. In: Conhecimento prudente para uma vida decente: "um discurso sobre as ciências" revisitado. 2. ed. São Paulo: Cortez, 2006. p. 777-821.

. Para além do pensamento abissal: das linhas globais a uma ecologia dos saberes. Novos estudos, São Paulo: CEBRAP, n. 79, p. 71-94, nov. 2007. Disponível em: <http:// www.scielo.br/pdf/nec/n79/04.pdf>. Acesso em: 10 maio 2010.

. Da ciência moderna ao novo senso comum. In: A crítica à razão indolente: contra o desperdício da experiência. 7. ed. São Paulo: Cortez, 2009. p. 55-117.

Schienbinger, Londa. O feminismo mudou a ciência? Tradução de Raul Fiker. Bauru: EDUSC, 2001. (Coleção Mulher)

Scotт, Joan Wallach. A cidadã paradoxal: as feministas francesas e os direitos do homem. Tradução de Élvio Antônio Funck. Florianópolis: Editora Mulheres, 2002.

\section{SOBRE A AUTORA}

Vívian Matias dos Santos é doutora em sociologia pela Universidade Federal do Ceará (UFC). Professora da Universidade Federal de Pernambuco (UFPE).

E-mail:vivianmsa@yahoo.com.br 